Original Research Paper

\title{
Gilsonite Modified Asphalt for Use in Pavement Construction
}

\author{
${ }^{1}$ Aliasghar Akbari Nasrekani, ${ }^{2}$ Mostafa Nakhaei, \\ ${ }^{3}$ Koorosh Naderi, ${ }^{4}$ Taher M. Abu-Lebdeh, ${ }^{4}$ Elham H. Fini and ${ }^{5}$ Sassan Aflaki \\ ${ }^{I}$ Department of Civil Engineering, School of Civil Engineering, \\ College of Engineering, University of Tehran, Tehran, Iran \\ ${ }^{2}$ National Center for Asphalt Technology, Auburn University, Alabama, USA \\ ${ }^{3}$ School of Civil and Environmental Engineering, Amirkabir University of Technology, Tehran, Iran \\ ${ }^{4}$ Department of Civil, Architectural and Environmental Engineering, \\ North Carolina A\&T State University, Greensboro, NC 27411, USA \\ ${ }^{5}$ Department of Civil and Environmental Engineering, The Catholic University of America, Washington, DC, USA
}

Article history

Received: 21-02-2018

Revised: 25-03-2018

Accepted: 2-04-2018

Corresponding Author:

Taher M. Abu-Lebdeh

Department of Civil,

Architectural and Environmental

Engineering, North Carolina

A\&T State University,

Greensboro, NC 27411, USA

Email: taher@ncat.edu

\begin{abstract}
Properties such as durability and moisture resistance of asphalt concrete significantly improve pavement service life. When siliceous aggregate is used, then preventing moisture damage and stripping become distinctly required. Typically, stripping could be prevented by either using antistripping agents or by modifying the binders. The anti-stripping agent achieve its purpose by changing the aggregates' affinity for water through changing the zeta potential (promote bitumen adsorption due to negative surface charge). On the other hand, modifications of binders promote interface bonding between aggregate particles and bitumen. However, the process of applying anti-stripping agents or adhesion promoters is typically costly and, in some cases, may negatively impact other performance characteristics of pavement. Accordingly, this paper examines the merit of applying natural bitumen (gilsonite) instead of typically used anti-stripping chemicals in order to both promote resistance to moisture damage and reduce construction cost in asphalt. In addition to being quite low-cost, Gilsonite has a chemical composition nearly similar to that of petroleum based asphalt which makes it very compatible with asphalt binder.
\end{abstract}

Keywords: Natural Bitumen, Gilsonite, Moisture Sensitivity, Antistripping, Fourier Transform Infrared Spectroscopy, Indirect Tensile Strength

\section{Introduction}

Moisture-induced damage is one of the main distresses of flexible pavement. The main mechanism of this distress is due to de-bonding of bitumen and aggregates caused by the presence of water. Bonding between bitumen and aggregates occurs mainly by polar components in bitumen bonding with active aggregate sites through mainly hydrogen bonding and Van der Waals interactions. It has been also reported that aggregate properties have higher impacts than bitumen characteristics on interfacial adhesion. In terms of bitumen components, aromatic hydrocarbons have less affinity to bond to aggregates than polar asphaltene and resins.

In addition, the functional groups that have stronger adhesion to aggregate active sites are carboxylic acids, sulfoxides, 2-Quinolone types, ketones, phenolics and nitrogen compounds (Petersen et al., 1982;
Petersen and Plancher, 1998; Plancher et al., 1977; Bhasin, 2003; Bhasin and Little, 2007). However, in the presence of water, carboxylic acids and sulfoxides are more prone to de-bonding.

Among the aforementioned groups, carboxylic acids provide the strongest bond with aggregate surfaces, but they are easily substituted with water. Sulfoxides and 2-Quinolone types have similar chemical behavior (Huang et al., 2005). It should be noted that the effect of the aforementioned functional groups are related to the types of aggregates. Siliceous materials are hydrophilic and their asphalt coating can be easily substituted with water, while the bitumen coating of limestone aggregates cannot be detached easily by the presence of water. Accordingly, some researchers used Fourier Transform Infrared spectroscopy (FTIR) and surface ionization to track the elements leaching from aggregates into the awater and examine surface mineralogy of stone 
particles after stripping occurred. It was observed that most stripped aggregates had less calcium, sodium and potassium on their surface where stripping was noticeable, indicating that stripping was accompanied by a significant cation dissolution. Other studies showed the addition of liquid anti-stripping agents could enhance interfacial bonds via polar ends of an anti-strip additive, which interact with the aggregate surface. It has been reported that among bitumen components, polar asphaltene and resins have a high affinity to bond to aggregates. Since natural bitumen (gilsonite) has a significant amount of polar components, including asphaltene and resins (Nader et al., 2014), this study examined its effectiveness relative to commonly used additives (such as lime) to improve bitumen-aggregate adhesion strength, particularly when exposed to water.

Natural bitumen is a crude-oil-based substance that moved upward from underground rock reservoirs to the earth's surface by passing through earth fractures. If natural bitumen reaches the earth's surface, it will create bitumen springs; if it remains near the earth's surface, it will gradually oxidize, solidify and finally turn into a solid, stiff substance named mineral bitumen. Gilsonite is a black and brittle mineral bitumen that can easily be crushed into powder (Ameri et al., 2011). Gilsonite, which is also called natural bitumen, asphaltite, uintaite, or asphaltum, is similar to hard petroleum bitumen (Huang et al., 2006). It is a resinous hydrocarbon that belongs to the hydrocarbonic class in modifier classification (Bahia et al., 2001).

Gilsonite can be used in asphalt mixtures either by premixing with bitumen before blending with aggregates or blending directly with aggregates prior to addition of bitumen. It has been suggested that wet process modification provide more prominent effect on the mechanical properties of asphalt mixture (Quintana et al., 2016). Gilsonite increases the viscosity of bitumen and reduces its penetration. Also, because of its higher softening point, gilsonite has higher stiffness compared to conventional bitumen (approximately 50 times higher than conventional bitumen). The results of a study conducted by Aflaki and Tabatabaee have revealed that increasing the content of gilsonite in bitumen increases the viscosity and improves the high-temperature performance of bitumen. However, gilsonite has a negative effect on intermediate and low-temperature performance (Huang et al., 2006; Aflaki and Tabatabaee, 2009; Ameri et al., 2012). Other studies have also shown that the introduction of gilsonite to asphalt can improve high-temperature performance of bitumen, while it causes brittleness in the lower-temperature range, resulting in thermal cracking of asphalt concrete
(Anderson et al., 1999; Rajbongshi and Das, 2009). The results of research conducted by Kök et al. (2011) have also shown that increasing the gilsonite content improves resistance to rutting. They concluded that application of gilsonite has an effect on hightemperature performance of bitumen similar to that of polymers such as Styrene-Butadiene-Styrene (SBS). It should be noted that use of gilsonite is more cost effective than polymers, especially considering the shortage of butadiene supply that has led to a further increase in SBS cost (Kök et al., 2011).

Thus, understanding the behavior of this material as a bitumen modifier is important, because not only does it improve the performance of asphalt concrete, it also reduces construction cost. Huang et al. (2005) used gilsonite as an intermediate layer to reduce stress concentration. This way, asphalt concrete acts as a threelayered composite mixture in which coarse aggregates are coated with a thin film of stiff gilsonite before being mixed with the bitumen. The results of their study showed improvement in resistance to moisture. However, the incorporation of gilsonite as an intermediate layer is not practical, because it is often accompanied by some difficulties such as dissolving in trichloroethylene to provide cover for aggregates (Huang et al., 2006; 2007). However, the moisture sensitivity of asphalt concrete fabricated with gilsonite-modified bitumen has not been evaluated. In this paper, FTIR spectroscopy and Indirect Tensile Strength (ITS) tests are used to evaluate the moisture sensitivity of gilsonite-modified mixtures. It is hypothesized that FTIR spectroscopy may help identify functional groups that can affect the moisture susceptibility of asphalt mixtures.

\section{Materials}

Crushed limestone aggregates and siliceous aggregates were used in this study; the aggregates were acquired from east and west of Tehran mines. The selected gradation for both aggregate types is presented in Fig. 1. Nominal maximum aggregate size was selected to be $12.5 \mathrm{~mm}$. Also, neat bitumen with a performance grade of PG 58-22 and 200 mesh gilsonite powder were used. Detailed properties of asphalt binders and gilsonite are presented in Table 1 and 2.

To prepare samples, 5 and $10 \%$ gilsonite (by weight of bitumen) was added to the bitumen and heated to $180^{\circ} \mathrm{C}$. The mixture was blended at $6500 \mathrm{rpm}$ for $60 \mathrm{~min}$ in a high-shear-rate mixer. Then, optimum bitumen content for an unmodified mixture was determined according to the Superpave mix design, assuming a design high air temperature of $39-40^{\circ} \mathrm{C}$. 


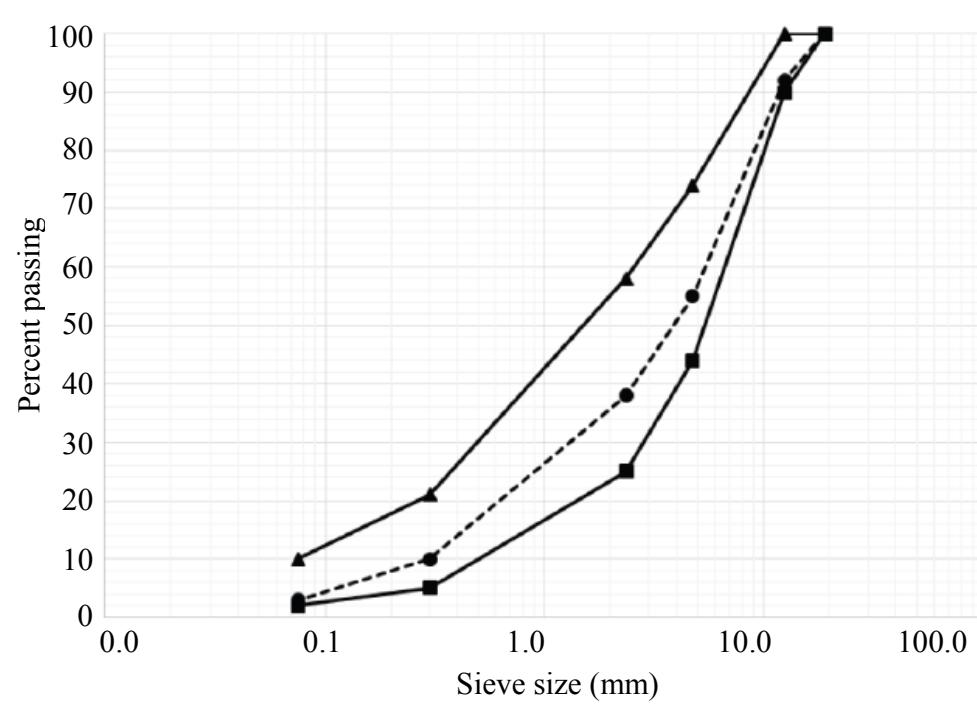

--๑--Aggregate gradation

$\longrightarrow$ Superpave upper limit

$\rightarrow-$ Superpave lower limit

Fig. 1: Aggregates gradation

Table 1: Physical properties and elemental analysis of gilsonite (SMC, 2016)

\begin{tabular}{|c|c|c|}
\hline Measured parameter & Results & Test method \\
\hline Ash Content, \%wt & $9-14$ & ASTM D3174 \\
\hline Moisture content, $\%$ wt & $\leq 3$ & ASTM D3173 \\
\hline Volatile matter, \%wt & 63 & ASTM D3175 \\
\hline Fixed carbon, $\%$ wt & 29 & ASTM D3172 \\
\hline Solubility in CS2, \%wt & 81 & ASTM D4 \\
\hline Specific gravity@25ㄷ & 1.11 & ASTM D3289 \\
\hline Normal heptane insolubles, $\%$ wt & 86 & ASTM D3279 \\
\hline Color in mass & Black & ------ \\
\hline Color in streak or powder & Brown & ------ \\
\hline Softening point, ${ }^{\circ} \mathrm{C}$ & $225 \pm 5$ & ASTM D36 \\
\hline Penetration@ $92{ }^{\circ} \mathrm{C}, 0.1 \mathrm{~mm}$ & 0 & ASTM D5 \\
\hline Solubility in tricholoroethylene & 56 & ASTM D2042 \\
\hline \multicolumn{3}{|l|}{ Element analysis } \\
\hline Carbon, \%wt & 74 & ASTM D5291 \\
\hline Hydrogen, \%wt & 7.1 & ASTM D5291 \\
\hline Nitrogen, \%wt & 0.67 & ASTM D5291 \\
\hline Oxygen, \%wt & 3.1 & Leco(s) Analyzer \\
\hline Sulphur, \%wt & 4 & Leco(s) Analyzer \\
\hline
\end{tabular}

Table 2: Physical properties of asphalt binders

\begin{tabular}{|c|c|c|c|c|}
\hline Measured parameter & Neat bitumen & Neat bitumen $+5 \%$ gilsonite & Neat bitumen $+10 \%$ gilsonite & Test method \\
\hline Penetration@25ㄷ, $0.1 \mathrm{~mm}$ & 101.6 & 64.6 & 47.7 & ASTM D5 \\
\hline 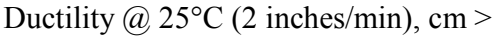 & 145 & 115.2 & 65.0 & ASTM D113 \\
\hline Softening point $(\mathrm{R} \& \mathrm{~B}),{ }^{\circ} \mathrm{C}$ & 46.9 & 51.2 & 54.7 & ASTM D36 \\
\hline Performance grade & PG 58-22 & PG 64-16 & PG 70-16 & ASTM D6373 \\
\hline Mixing temperature $\left({ }^{\circ} \mathrm{C}\right)$ & $110-114$ & $119-123$ & $128-132$ & ASTM D2493 \\
\hline Compaction temperature $\left({ }^{\circ} \mathrm{C}\right)$ & 104-107 & $113-116$ & $121-124$ & ASTM D2493 \\
\hline
\end{tabular}

Optimum bitumen content at the target air void of $4 \%$ was achieved at $5.5 \%$ by weight of the total mixture. After that, 60 samples were compacted by a Superpave Gyratory Compactor (SGC) at the target air void of 7\%.

While the mold containing loose mixture is being rotated at a rate of 30 revolutions per minute and an angle of 1.25 degrees to the vertical axis, a $600 \mathrm{kPa}$ static load is placed on the specimen through use of a ram. The SGC was adjusted to compact the mixtures until the air void was $7 \pm 0.5 \%$.

\section{Testing Program}

In this study, FTIR and ITS tests were conducted on bitumen and asphalt concrete, respectively. 


\section{Fourier Transform Infrared Spectroscopy}

Fourier transform infrared spectroscopy was performed using an appropriate spectrometer. About 1 gr of gilsonite powder was mixed with 100 gr dried potassium bromide powder in an agate mortar. Then $1 \mathrm{GPa}$ pressure was applied, using a hydraulic press to coalesce the sample into a semi-transparent disk. For semi-solid bituminous samples, dichloromethane was used as a solvent to dilute neat and modified bitumen. Samples were dissolved in dichloromethane with a concentration of $30 \mathrm{gl}^{-1}$ and injected into the liquid cell between potassium bromide plates. The solvent was then evaporated under air flow. Both bitumen samples and the gilsonite powder disk were examined in the range between 4000 and $400 \mathrm{~cm}^{-1}$ with 32 scans per analysis at a resolution of $4 \mathrm{~cm}^{-1}$.

Quantitative comparison of the results was performed using spectrometric indices proposed by Lamontagne et al. (2001). These structural and functional indices are calculated using valley-to-valley integration between peak points (Fig. 2). Based on definitions given by Lamontagne et al. (2001), carbonyl and sulfoxide indices were determined using Equations 1 to 3:

Carbonyl Index $=A_{1700} / \Sigma A$

Sulfoxide Index $=A_{1030} / \Sigma A$

where, $\Sigma A$ is defined as:

$$
\begin{aligned}
& \Sigma A=A_{1700}+A_{1600}+A_{1460}+A_{1376}+A_{1030} \\
& +A_{864}+A_{814}+A_{743}+A_{724}+A_{(2953+29232862)}
\end{aligned}
$$

In these equations $A_{x}$ is the area under the peak at $x$ $\left(\mathrm{cm}^{-1}\right)$ wavenumber.

\section{Indirect Tensile Strength Test}

The purpose of this test is to determine the effect of saturation and freeze-thaw conditioning on the indirect tensile strength of cylindrical specimens. To this end, samples were divided into two subsets, dry and wet. One subset was wrapped with heavy duty leak-proof plastic, then placed in a water bath and kept at $25^{\circ} \mathrm{C}$ for two hours before conducting the ITS test; the other subset was subjected to an absolute vacuum pressure of $20 \mathrm{kPa}$ to obtain $70-80$ percent saturation according to AASHTO T283. After saturation, vacuum-saturated specimens, which were wrapped with a heavy duty plastic bag, were kept in a freezer at $-18^{\circ} \mathrm{C}$ for $16 \mathrm{~h}$. Before conducting the ITS test, frozen specimens were immediately placed in a water bath of $60^{\circ} \mathrm{C}$ for $24 \mathrm{~h}$, followed by a 2 -h water bath at $25^{\circ} \mathrm{C}$.

After removing specimens from the water bath, their thickness and diameter were determined and they were immediately placed between loading strips. A load was applied according to AASHTO T283 at a constant rate of 50 millimeters per minute and the maximum load each specimen sustained during the test was recorded. Therefore, the ITS can be calculated.

Another parameter that can be determined from the results of the ITS test is fracture energy to failure, which is defined as the area under the loaddeformation curve to failure, as shown in Fig. 3 (Khodary, 2010). This parameter can be calculated for dry and wet specimens and the ratio of fracture energy to failure of wet specimens to those of dry specimens can be determined.
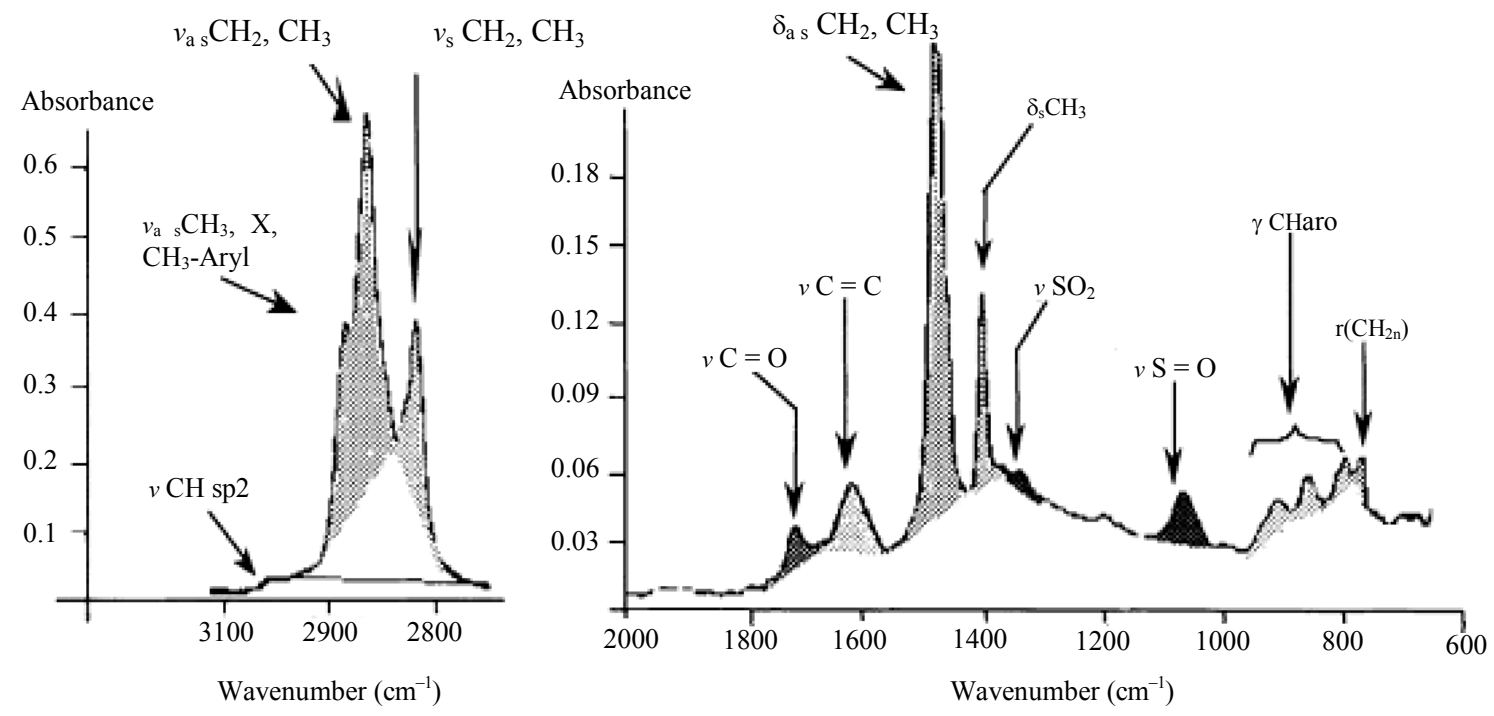

Fig. 2: FTIR spectrum of a 4000-400 $\mathrm{cm}^{-1}$ original bitumen and visualization of valley-to-valley area integration (Lamontagne et al., 2001) 


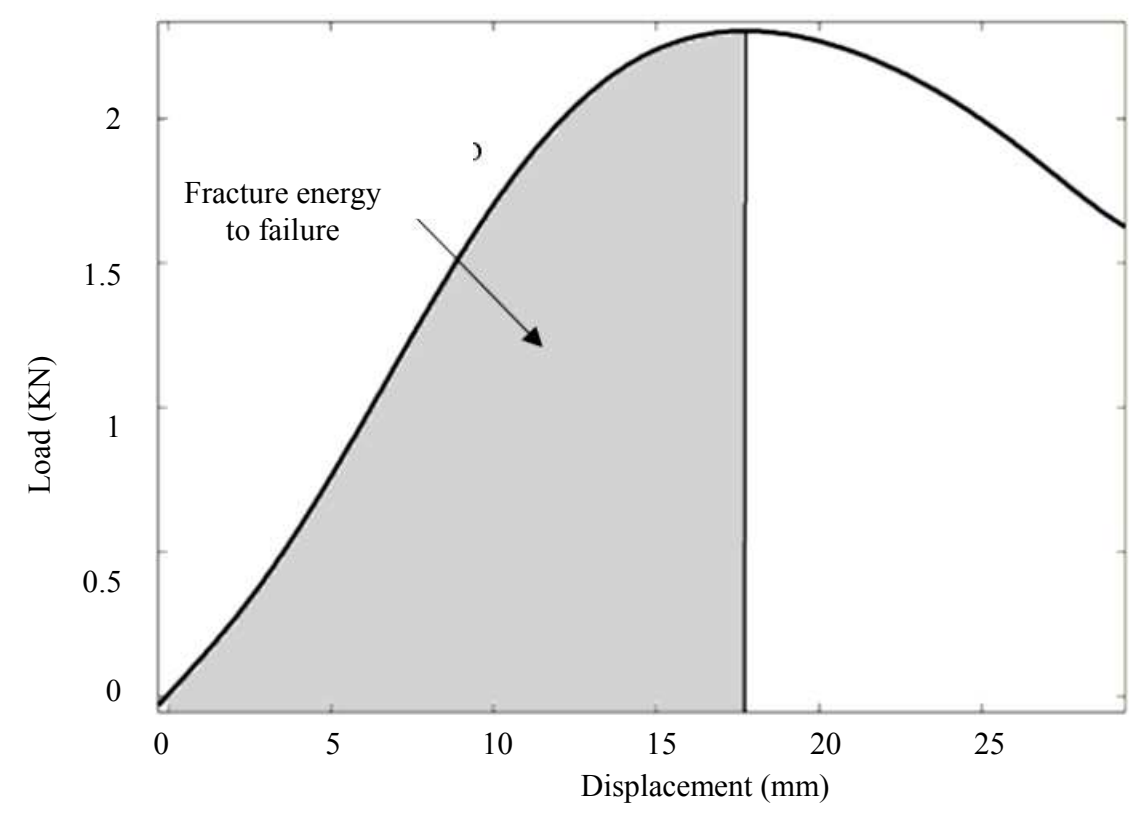

Fig. 3: Definition of fracture energy to failure

\section{Results and Discussion}

Fourier Transform Infrared Spectroscopy and Indirect Tensile Strength tests were conducted according to the aforementioned procedures. In the following, the test results are interpreted.

\section{Results of the FTIR Spectroscopy}

As established in the introduction in detail, FTIR spectroscopy and functional group indices of bitumen may help us to anticipate moisture sensitivity of bitumen-aggregate. Infrared spectra of the neat bitumen and gilsonite powder are presented in Fig. 4. Both spectra have been normalized with respect to intensity at $2920 \mathrm{~cm}^{-1}$ wavenumber (Li et al., 2015; Zofka, 2013). The similarity of the spectra in wavenumber domain of spectroscopy and especially at 2920,2850,1600, 1455, 1375 and $1030 \mathrm{~cm}^{-1}$ is noticeable in this figure. Both samples show peaks at these wavenumbers. Absorbance at 2920 and $2850 \mathrm{~cm}^{-1}$ are related to asymmetric and symmetric $\mathrm{C}-\mathrm{H}$ stretching vibrations, respectively. The peak intensity at $2920 \mathrm{~cm}^{-1}$ indicates the presence of long aliphatic chains in both gilsonite and refined bitumen. As shown in Fig. 4, there is no distinct intensity peak at $1700 \mathrm{~cm}^{-1}$ relating to carbonyl compounds for gilsonite powder. Peak intensity at $1600 \mathrm{~cm}^{-1}$, which is related to stretching vibrations of the $\mathrm{C}=\mathrm{C}$ double bond of aromatics, can be identified for both gilsonite powder and neat bitumen. However, this peak intensity is more prominent for neat bitumen. Peak intensity at 1450 and $1375 \mathrm{~cm}^{-1}$, due to deforming vibrations of asymmetric and symmetric $\mathrm{C}-\mathrm{CH} 3$ bonds, are noticeable for both materials. One of the differences between gilsonite powder and neat bitumen is the high intensity of the peak at $1030 \mathrm{~cm}^{-1}$ relating to sulfoxide group. This finding is consistent with the results of elemental analysis of gilsonite powder presented in Table 1. Peaks between 700 to $900 \mathrm{~cm}^{-1}$ wavenumbers, which are related to aromatic compounds, are also noticeable for both gilsonite powder and neat bitumen. As just discussed, there are many similarities between functional groups of gilsonite powder and neat bitumen (especially at wavenumbers above $1400 \mathrm{~cm}^{-1}$ ). This result conforms to the gilsonite formation hypothesis which states that gilsonite is a natural bitumen-based material (Ameri et al., 2011). Figure 5 shows FTIR spectra for unmodified bitumen and gilsonite-modified bitumen

For quantitative evaluation of these spectra, spectrometric indices proposed by Lamontagne et al. (2001) have been used; the results are presented in Fig. 6 . It can be observed that both carbonyl and sulfoxide indices are decreased by blending gilsonite with neat bitumen. Since a high-intensity peak was observed for gilsonite powder in Fig. 4 at $1030 \mathrm{~cm}^{-1}$, the decrease in sulfoxide index was not expected. It seems that increases in other aliphatic functional groups and asphaltenes have resulted in an overall reduction of the sulfoxide ratio in the bitumen. As it was discussed in the introduction part, an increase in sulfoxide groups and carboxylic acids of bitumen will result in lower moisture resistance of asphalt concrete. Thus, it can be deduced that blending gilsonite with neat bitumen will result in reduced moisture sensitivity and increased Tensile Strength Ratio (TSR) for asphalt mixtures. 


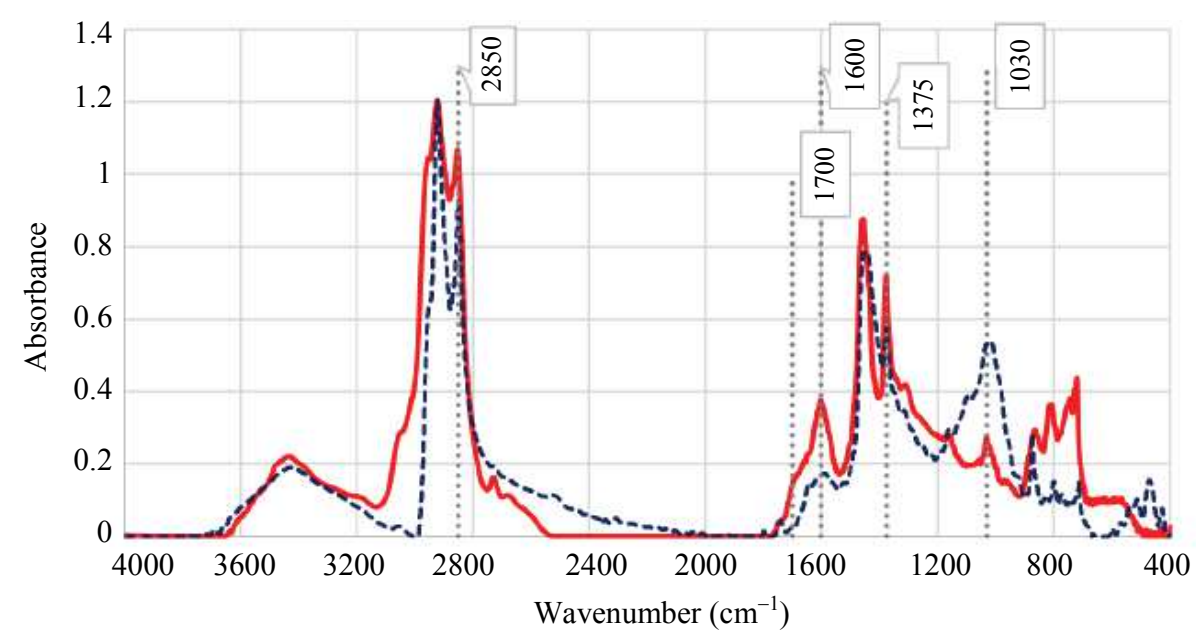

Neat Bitumen

----Gilsonite Powder

Fig. 4: FTIR spectra of neat bitumen and gilsonite powder

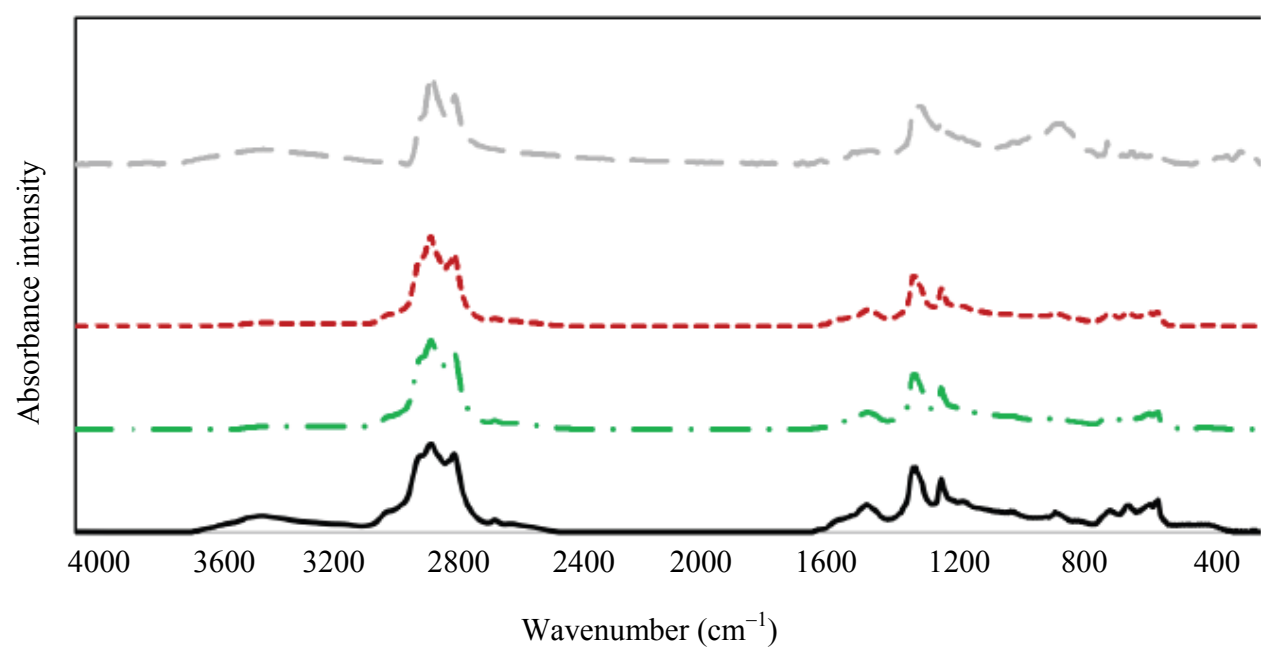

$\longrightarrow$ Neat Bitumen $\quad-\cdot-5 \%$ Gilsoneit

$----10 \%$ Gilsonite

- Gilsonite Powder

Fig. 5: FTIR spectra for unmodified bitumen and gilsonite-modified bitumen

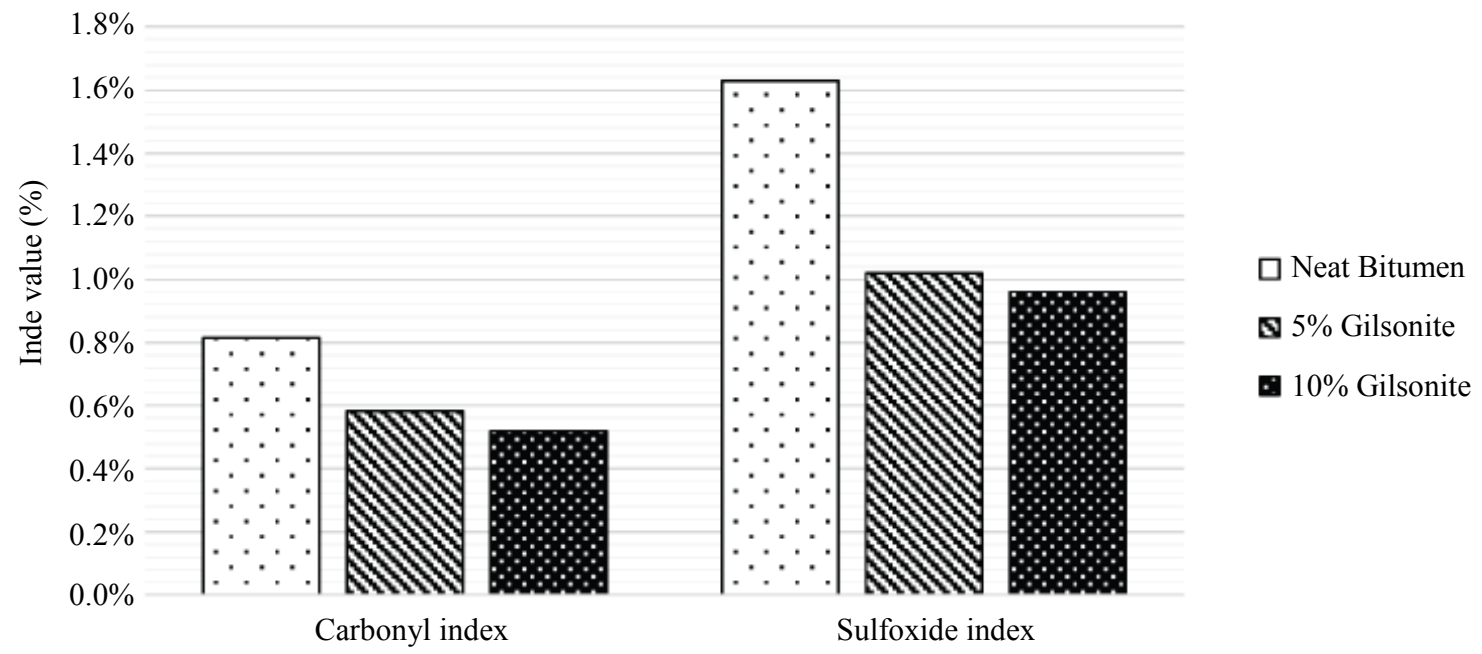

Fig. 6: Sulfoxide and carbonyl indices for unmodified bitumen and gilsonite-modified bitumen 


\section{Results of the ITS Test}

Figures 7 and 8 illustrate the results of the indirect tensile strength test for lime and siliceous aggregate mixtures, respectively. TSR values for lime and siliceous aggregate mixtures are illustrated in these figures as well. As shown, a further increase in gilsonite content results in more increase in indirect tensile strength for either lime or siliceous aggregates and dry or freeze-thaw conditioned specimens. For lime aggregate mixtures, 5 and $10 \%$ gilsonite increase ITS values 39 and $66 \%$, respectively; for conditioned specimens, the increases are 49 and $79 \%$. Thus, it can be inferred that the effect of gilsonite on the indirect tensile strength of conditioned specimens is more significant compared to dry specimens. Although it can be stated that an increase in gilsonite content increases ITS values generally, there is no straight-line relationship between values. This may be due to the fact that gilsonite makes bitumen stiffer and increases its viscosity, which consequently makes asphalt concrete stiffer with higher ITS values. For siliceous aggregate mixtures, a similar trend can be observed. Substitution of 5 and $10 \%$ gilsonite with neat bitumen increases ITS values 51 and $88 \%$ for dry specimens and raises ITS values 240 and $323 \%$ for conditioned specimens. This significant improvement supports the finding stated earlier that gilsonite further increases ITS of conditioned specimens compared to dry specimens.

Variance analysis of ITS test results was performed and the results are presented in Table 3. As shown, for both dry and wet specimens, the gilsonite content has a significant effect on ITS values (p-values are below $0.05)$. It can be also concluded that aggregate type has significant impact on ITS results of dry specimens, but is not statistically effective on wet specimens. Furthermore, although the interaction between aggregate type and gilsonite content is statistically significant for both dry and freeze-thaw conditioned specimens, the effectiveness of gilsonite modification for aggregate type is more pronounced in conditioned specimens ( $\mathrm{p}$-value $<0.0001$ ).

By comparison of TSR values in Figs. 7 and 8, Control asphalt concrete has a TSR of $85 \%$ for lime aggregate and $36 \%$ for siliceous aggregate. Obviously, it is ascribed to the anti-stripping effect of limestone due to the presence of $\mathrm{Ca}(\mathrm{OH})_{2}$, which strengthens bonds between bitumen and aggregates. In siliceous aggregates, the presence of $\mathrm{SiO}_{2}$ induces asphalt concrete to withstand much lower stress levels before failure, since the hydrophilic nature of these aggregates causes them to readily leave bitumen for water, resulting in a sharp drop in indirect tensile strength.

It can be observed in Figs. 7 and 8 that TSR values increase with gilsonite content for both types of aggregates. The results show that gilsonite has a positive impact on TSR values. Asphalt concrete modified with 5 and $10 \%$ gilsonite increases TSR values $8 \%$ and $125 \%$ in lime and siliceous aggregate mixtures, respectively. It is noteworthy that change in gilsonite content does not affect TSR equally for both types of aggregates. Therefore, if just resistance to moisture is important, using $5 \%$ gilsonite with neat bitumen will be enough.

From the results, it can be concluded that modifying bitumen with gilsonite increases TSR in lime aggregate asphalt concrete and substantially in siliceous aggregate mixtures. In other words, gilsonite improves moisture sensitivity of asphalt concrete. It is worthy to mention that for both aggregate types, gilsonite-modified asphalt concrete has TSR values more than $80 \%$.

Figures 9 and 10 show the fracture energy until failure of lime and siliceous aggregate asphalt concrete calculated from the ITS test results. As can be seen, increasing the gilsonite content increases the fracture energy of asphalt concrete in dry and wet condition for both aggregate types.

Table 3: Variance analysis of ITS test results

\begin{tabular}{|c|c|c|c|c|c|c|c|c|c|}
\hline \multirow[b]{3}{*}{ Source } & & & \multirow[b]{3}{*}{$\mathrm{df}$} & \multirow{2}{*}{\multicolumn{2}{|c|}{ Mean Square }} & \multirow{2}{*}{\multicolumn{2}{|c|}{ F-Value }} & \multirow{2}{*}{\multicolumn{2}{|c|}{$\begin{array}{l}\text { p-value } \\
\text { Prob }>\text { F }\end{array}$}} \\
\hline & \multicolumn{2}{|c|}{ Sum of Squares } & & & & & & & \\
\hline & ITS $_{\text {Dry }}$ & ITS $_{\text {Wet }}$ & & ITS $_{\text {Dry }}$ & ITS $_{\text {Wet }}$ & ITS $_{\text {Dry }}$ & ITS $_{\text {Wet }}$ & ITS $_{\text {Dry }}$ & ITS $_{\text {Wet }}$ \\
\hline Model & 327816.0 & 558245.4 & 4 & 81954.0 & 139561.4 & 126.75 & 211.40 & $<0.0001$ & $<0.0001$ \\
\hline A-gilsonitecontent & 321903.0 & 450244.0 & 1 & 321903.0 & 450244.0 & 497.84 & 682.00 & $<0.0001$ & $<0.0001$ \\
\hline B-aggregatetype & 6.5 & 61826.5 & 1 & 6.5 & 61826.5 & 0.01 & 93.65 & 0.9219 & $<0.0001$ \\
\hline $\mathrm{AB}$ & 3119.9 & 22780.1 & 1 & 3119.9 & 22780.1 & 4.83 & 34.51 & 0.0468 & $<0.0001$ \\
\hline $\mathrm{A} 2$ & 2786.6 & 23394.7 & 1 & 2786.6 & 23394.7 & 4.31 & 35.44 & 0.0583 & $<0.0001$ \\
\hline Residual & 8405.7 & 8582.4 & 13 & 646.6 & 660.2 & & & & \\
\hline Lack of fit & 39.3 & 6310.2 & 1 & 39.3 & 6310.2 & 0.06 & 33.32 & 0.8164 & $<0.0001$ \\
\hline Pure error & 8366.5 & 2272.2 & 12 & 697.2 & 189.4 & & & & \\
\hline Cor total & 336221.7 & 566827.8 & 17 & & & & & & \\
\hline
\end{tabular}




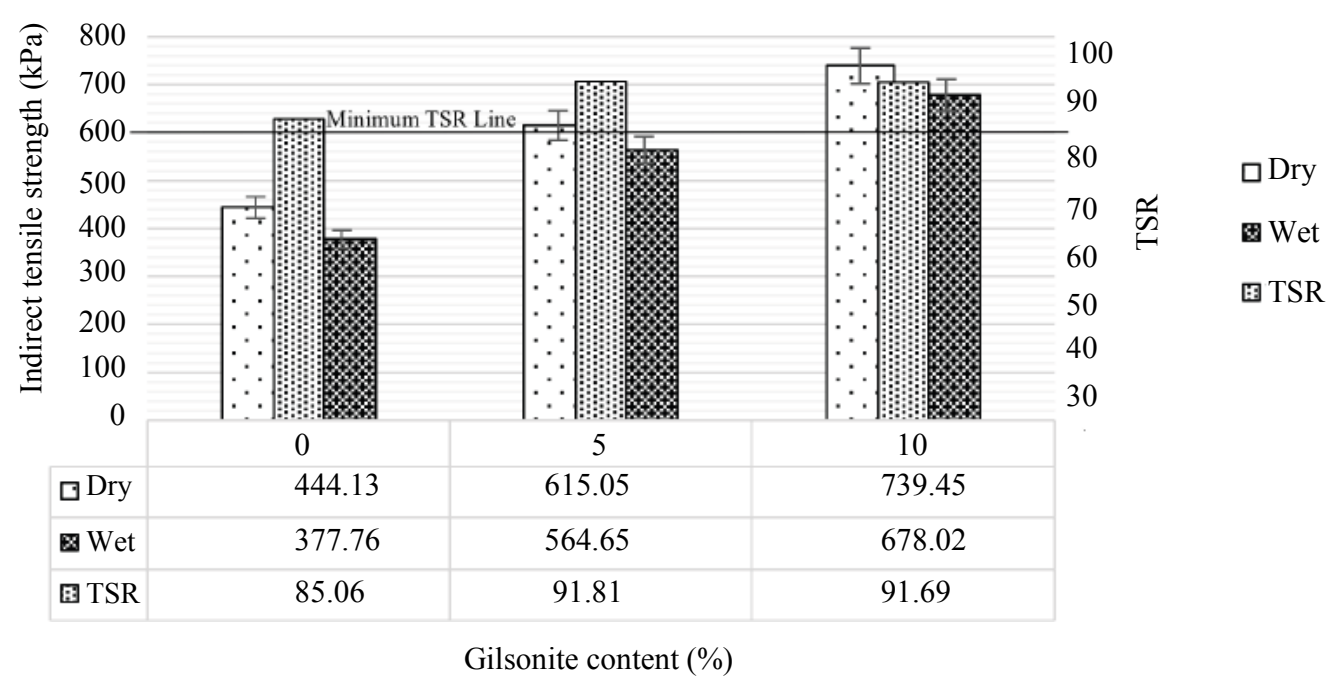

Fig. 7: Indirect tensile strengths vs. gilsonite content for lime aggregate mixtures

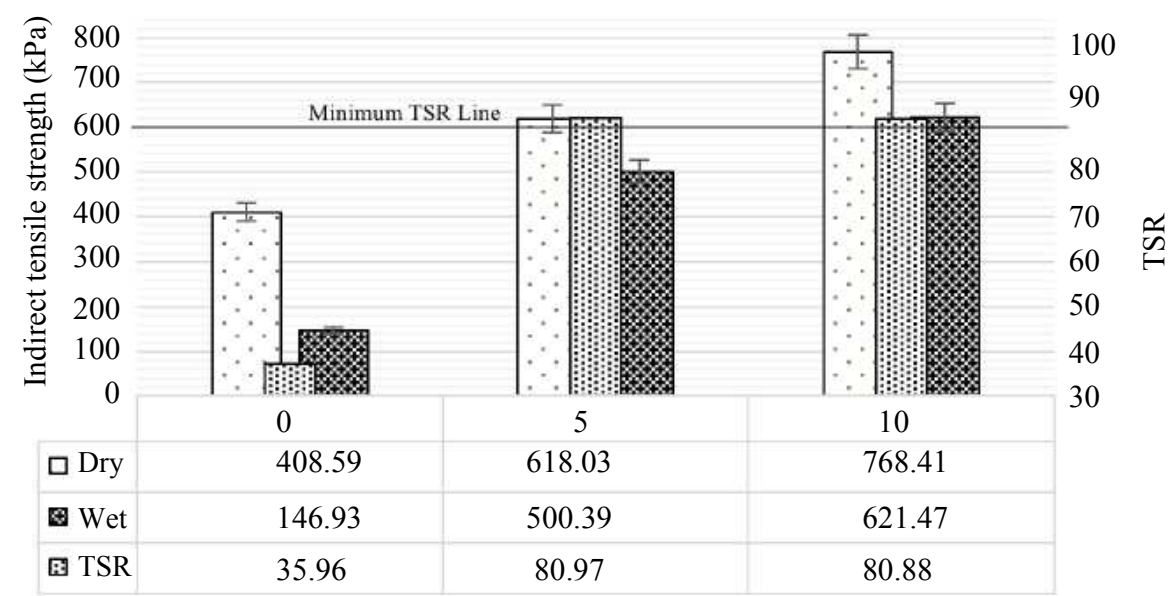

Gilsonite content (\%)

Fig. 8: Indirect tensile strengths vs. gilsonite content for siliceous aggregate mixtures

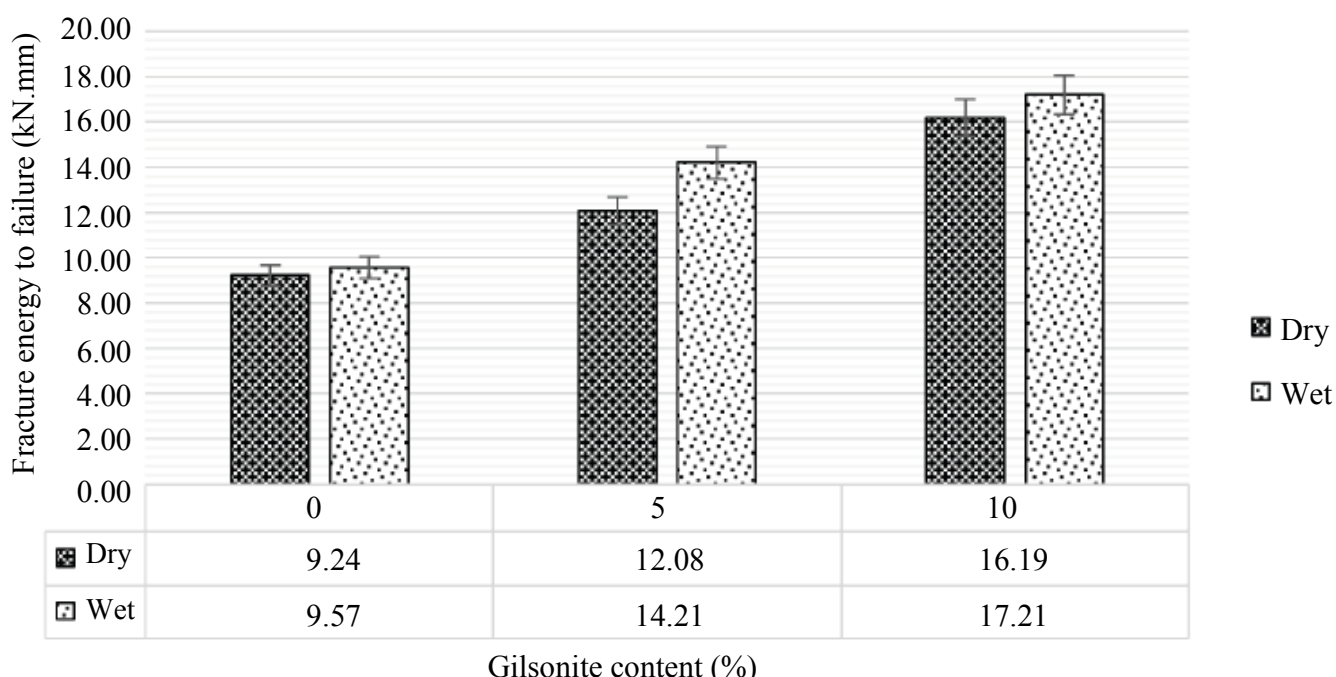

Fig. 9: Fracture energy to failure vs. gilsonite content for limestone aggregate mixtures 


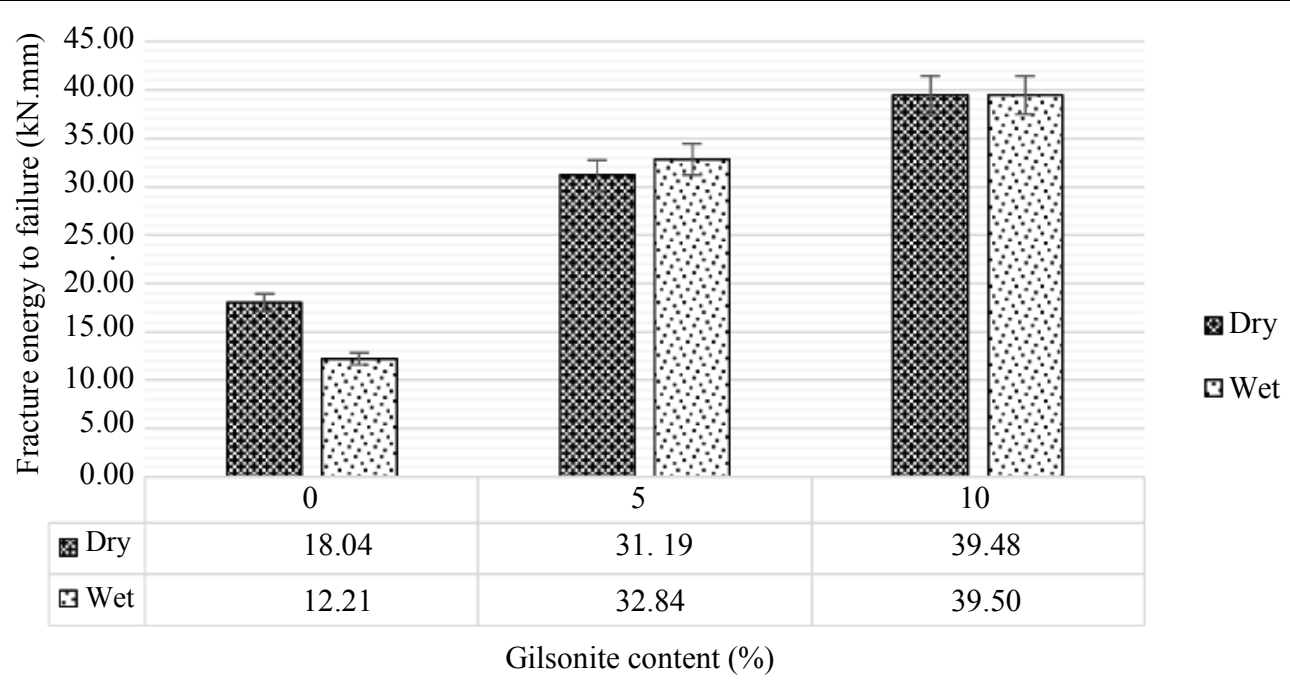

Fig. 10: Fracture energy to failure vs. gilsonite content for siliceous aggregate mixtures

This may be due to an increase in asphaltene content of modified bitumen and the stiffening effect of gilsonite. Figures 9 and 10 show that siliceous aggregate mixtures have higher values of fracture energy to failure compared to limestone aggregate mixtures, but obviously the moisture sensitivity of siliceous aggregate mixtures is higher than that of limestone aggregate mixtures. Thus, although some previous studies (Ameri et al., 2013; Xiao et al., 2012) suggested the use of fracture energy to failure and Fracture Energy Ratio (FER - defined as the fracture energy of conditioned specimens divided by the fracture energy of unconditioned specimens), these may not be proper indicators of moisture sensitivity, based on the results of this study. Furthermore, for all specimens with the exception of the control mixture for siliceous aggregates, the fracture energy of conditioned specimens is higher than that of unconditioned specimens, which supports the aforementioned claim. Therefore, not only is there no consistency between FER and TSR values, but also an absolutely unreasonable adverse relation can be observed.

\section{Conclusion}

Gilsonite is a mineral material that has a lower price than bitumen. Gilsonite can be used as a modifier of bitumen to improve performance-related properties of asphalt concrete. In this study, the moisture sensitivity of gilsonite-modified mixtures was evaluated using Fourier transform infrared spectroscopy and modified Lottman tests. The results of this study are as follows:

- The functional groups of gilsonite powder are similar to those of neat bitumen, which indicates that gilsonite is a bitumen-based material

- The results of the FTIR test are coincident with those of the ITS test (TSR values). Thus, using FTIR can be a useful method to gain insight on the moisture sensitivity of asphalt concrete through testing bitumen, which is both cost-effective and less time-consuming

- The effect of adding gilsonite on improving the moisture sensitivity of mixtures containing siliceous aggregates was more significant compared to that of lime aggregates mixtures. It indicates that Gilsonite can be considered as a good anti-stripping agent for siliceous aggregates

- Gilsonite-modified asphalt mixtures have higher TSR values than control asphalt mixtures which results in higher resistance to moisture damage. Therefore, the use of gilsonite-modified mixtures is recommended in humid areas

- For both aggregate types and both dry and wet specimens, increase in gilsonite content increases ITS values

- For both aggregate types, a further increase in gilsonite does not affect TSR values i.e., addition of $5 \%$ gilsonite to asphalt mixture improves TSR values significantly, but increment of gilsonite content from 5 to $10 \%$ does not affect TSR values

- An increase in gilsonite content increases the fracture energy to failure value, which is related to the resistance of asphalt concrete to cracking. However, by comparing the results, it has been shown that FER is not a good indicator of moisture sensitivity .i.e. FTIR and AASHTO T283 test results are consistent particularly in trends with gilsonite content, but not only is there no consistency between FER and TSR values, but also an absolutely unreasonable adverse relation can be observed

\section{Acknowledgement}

The authors would like to thank their colleagues for their collaborations. We also thank very much the anonymous reviewers whose useful criticisms, comments and suggestions have helped strengthen the content and the quality of the paper. 


\section{Author's Contributions}

Aliasghar Akbari Nasrekani, Mostafa Nakhaei and Koorosh Naderi: Performed laboratory experiments and conducted data analysis of the research. Also, participated in writing the manuscript.

Taher M. Abu-Lebdeh, Elham H. Fini and Sassan Aflaki: Provided the research topic and guided the research development, experimental plan and data analysis. Also, participated in writing the manuscript.

\section{Ethics}

No part of this article may be reproduced without written permission from the publisher or authors.

\section{References}

Aflaki, S. and N. Tabatabaee, 2009. Proposals for modification of Iranian bitumen to meet the climatic requirements of Iran. Construct. Build. Mater., 23: 2141-2150. DOI: 10.1016/j.conbuildmat.2008.12.014

Ameri, M., A. Mansourian, S.S. Ashani and G. Yadollahi, 2011. Technical study on the Iranian Gilsonite as an additive for modification of asphalt binders used in pavement construction. Construct. Build. Mater., 25: 1379-1387. DOI: 10.1016/j.conbuildmat.2010.09.005

Ameri, M., A. Mansourian and A.H. Sheikhmotevali, 2012. Investigating effects of ethylene vinyl acetate and gilsonite modifiers upon performance of base bitumen using Superpave tests methodology. Construct. Build. Mater., 36: 1001-1007.

Ameri, M., S. Kouchaki and H. Roshani, 2013. Laboratory evaluation of the effect of nanoorganosilane antistripping additive on the moisture susceptibility of HMA mixtures under freeze-thaw cycles. Construct. Build. Mater., 48: 1009-1016.

Anderson, D., D. Maurer, T. Ramirez, D. Christensen and M. Marasteanu et al., 1999. Field performance of modified asphalt binders evaluated with superpave test methods: I-80 test project. J. Trans. Res. Board, 1661: 60-68. DOI: 10.3141/1661-10

Bahia, H.U., D. Hanson, M. Zeng, H. Zhai and M. Khatri and R. Anderson, 2001. Characterization of modified asphalt binders in superpave mix design (No. Project 9-10 FY'96).

Bhasin, A., 2003. Development of methods to quantify bitumen-aggregate adhesion and loss of adhesion due to water. Doctoral dissertation, Texas A\&M University. Texas A\&M University.

Bhasin, A. and D.N. Little, 2007. Characterization of aggregate surface energy using the universal sorption device. J. Mater. Civil Eng.
Huang, S., R. Robertson, J. Branthaver and P.J. Claine, 2005. Impact of lime modification of asphalt and freeze-thaw cycling on the asphalt-aggregate interaction and moisture resistance to moisture damage. J. Mate. Civil Eng., 17: 711-718. DOI: 10.1061/(ASCE)0899-1561(2005)17:6(711)

Huang, B., G. Li and X. Shu, 2006. Investigation into threelayered HMA mixtures. Composites Part B: Eng., 37: 679-690. DOI: 10.1016/j.compositesb.2005.08.005

Huang, B., X. Shu, G. Li and L. Chen, 2007. Analytical modeling of three-layered HMA mixtures. Int. J. Geomechanics, 7: 140-148. DOI: 10.1061/(ASCE)1532-3641(2007)7:2(140)

Khodary, M.H.F., 2010. Evaluation of fatigue resistance for modified asphalt concrete mixtures based on dissipated energy concept. Darmstadt, Technische Universität.

Kök, B.V., M. Yilmaz and M. Guler, 2011. Evaluation of high temperature performance of SBS+ Gilsonite modified binder. Fuel, 90: 3093-3099. DOI: $10.1016 /$ j.fuel.2011.05.021

Lamontagne, J., P. Dumas, V. Mouillet and J. Kister, 2001. Comparison by Fourier Transform Infrared (FTIR) spectroscopy of different ageing techniques: Application to road bitumens. Fuel, 80: 483-488. DOI: 10.1016/S0016-2361(00)00121-6

Li, K., M. Vasiliu, C.R. Mcalpin, Y. Yang and D.A. Dixon et al., 2015. Further insights into the structure and chemistry of the Gilsonite asphaltene from a combined theoretical and experimental approach. Fuel, 157: 16-20. DOI: 10.1016/j.fuel.2015.04.029

Nader, N., S. Song, N. Kim and C. Namjun, 2014. Chemical characterization of gilsonite bitumen. J. Petroleum Environ. Biotechnol., 5: 1-10. DOI: 10.4172/2157-7463.1000193

Petersen, J., H. Plancher, E. Ensley, R. Venable and G. Miyake, 1982. Chemistry of asphaltaggregate interaction: relationship with pavement moisturedamage prediction test. (No. 843).

Petersen, J.C. and H. Plancher, 1998. Model studies and interpretive review of the competitive adsorption and water displacement of petroleum asphalt chemical functionalities on mineral aggregate surfaces. Petroleum Sci. Technol., 16: 89-131. DOI: $10.1080 / 10916469808949774$

Plancher, H., S.M. Dorrence and J.C. Petersen, 1977. Identification of chemical types in asphalts strongly adsorbed at the asphalt-aggregate interface and their relative displacement by water. [Moisture damage to roads].

Quintana, H.A.R., J.A.H. Noguera and C.F.U. Bonells, 2016. Behavior of gilsonite-modified hot mix asphalt by wet and dry processes. J. Mater. Civil Eng., 28: 04015114.

DOI: 10.1061/(ASCE)MT.1943-5533.0001339 
Rajbongshi, P. and A. Das, 2009. Estimation of temperature stress and low-temperature crack spacing in asphalt pavements. J. Trans. Eng.

DOI: 10.1061/(ASCE)TE.1943-5436.0000050

SMC, 2016. http://www.sormakmine.com/

Xiao, F., W. Zhao, T. Gandhi and S.N. Amirkhanian, 2012. Laboratory investigation of moisture susceptibility of long-term saturated warm mix asphalt mixtures. Int. J. Pavement Eng., 13: 401-414.
Zofka, A., 2013. Evaluating applications of field spectroscopy devices to fingerprint commonly used construction materials. Trans. Res. Board. DOI: $10.17226 / 22770$ 